\title{
Ontogenetic patterns of habitat use by reef-fish in a Marine Protected Area network: a multi-scaled remote sensing and in situ approach
}

\author{
Delisse M. Ortiz ${ }^{*}$, Brian N. Tissot \\ School of Earth and Environmental Science, Washington State University, 14204 NE Salmon Creek Avenue, Vancouver, \\ Washington 98686-9600, USA
}

\begin{abstract}
A network of Marine Protected Areas (MPAs) on the west coast of the island of Hawaii (West Hawaii) has been shown to vary in its effectiveness to replenish depleted aquarium fish stocks. To determine the abundance and distribution of habitats needed to better design and manage MPAs in Hawaii, underwater video transects, remote sensing data and a benthic classification scheme were combined to develop a map of reef habitats previously identified as important to the life history of aquarium fish and other reef species. Using these maps, an assessment was conducted to quantify habitat use by different life history stages of the most commonly live-caught aquarium fish, the yellow tang Zebrasoma flavescens, in existing MPAs. Rugosity, small reef features (i.e. percent cover of dominant reef species) and the abundance and size of fish were quantified in 115 circular plots to determine the accuracy of mapping efforts and the distribution of fish life history stages across the reef in 4 MPAs. Visual classification and mapping of habitat types was $93 \%$ accurate and consistent with percent cover of substrates quantified at the quadrat level. The different life history stages of yellow tangs were distributed along distinct habitat types in all of the MPAs examined. New recruits and juveniles of the yellow tang showed similar patterns of habitat use among sites and were associating with coral-rich areas and patches of the finger coral Porites compressa. In contrast, the distribution and abundance of adults varied greatly within and among sites. The development of a ground-truthed habitat map allowed a holistic examination of habitat use by yellow tang, including most life history stages, which provides key information for the design of MPAs and the advancement of ecosystem-based management.
\end{abstract}

KEY WORDS: Habitat mapping · Ontogenetic patterns $\cdot$ Habitat use $\cdot$ Coral reefs $\cdot$ Aquarium fish . Marine Protected Area network

Resale or republication not permitted without written consent of the publisher

\section{INTRODUCTION}

One important goal of reef-fish management is to identify the post-settlement processes driving the abundance and distribution of reef-fish. This is because the success of Marine Protected Areas (MPAs) in conserving reef-fish lies in knowing and conserving a range of life history stages and naturally regulating mechanisms (Hixon \& Webster 2002). Understanding population dynamics requires an understanding of the habitats influencing the individual life stages of reeffish across multiple spatial scales (Underwood et al.
2000). The patchiness typical of coral reefs creates habitats at multiple scales, each with distinctive features that may influence reef-fish at different life stages (Levin 1991, 1992). Reef-fish may associate with particular small-scale features such as percent cover of dominant species or rugosity (Tolimieri 1995, Friedlander \& Parrish 1998, Aburto-Oropeza \& Balaart 2001, Dahlgren \& Eggleston 2001), mid-scale features such as large swaths of contiguous habitat type (Fowler 1990, Green 1996, Meekan \& Choat 1997, Kendall et al. 2003) and large-scale features such as reef shape and morphology (Friedlander \& Brown 2003) across 
their life span. The availability and quality of reef habitat, in turn, can affect the post-settlement demography of reef-fish directly by providing refuge from predation (Hixon \& Beets 1993) or indirectly by modifying biological interactions among different species (Menge et al. 1985, Hixon \& Mark 1997). Hence, the abundance and distribution of many life history stages of reef-fish can best be explained by identifying and quantifying the abundance and distribution of habitats necessary for successful recruitment, growth and reproduction (Doherty \& Williams 1988, Tupper \& Boutilier 1995, Friedlander \& Parrish 1998).

In 1999 a network of 9 fishery replenishment areas (FRAs) was established on the west coast of the island of Hawaii (hereafter, West Hawaii) in response to declines of reef-fish taken by aquarium collectors. FRAs are MPAs where the collecting of live fish for the aquarium trade is prohibited. Five years of monitoring in these areas has revealed significant increases in the overall abundance of aquarium fish after the closure of FRAs (Walsh et al. 2004b). However, FRAs varied in their effectiveness to replenish fish populations, with only 4 of the 9 areas displaying significant increases in the most commonly collected aquarium fish, the yellow tang Zebrasoma flavescens (Tissot et al. 2004). Variation in the effectiveness of the FRA network in West Hawaii has been associated with several factors such as the strength of recruitment (Tissot et al. 2004) and the abundance of the finger coral Porites compressa, which may be important habitat for the survival and growth of juvenile yellow tang (Tissot et al. 2003, Walsh et al. 2004b) and other fish (Walsh 1987). These results suggest that the abundance and distribution of habitats is an important factor influencing the effectiveness of the FRA network. Thus, in order to design and effectively manage MPAs, it is important to understand the spatial variation of habitats in relation to the distribution and abundance of the life stages of reef-fish.

Characterization and description of habitats and their associations with reef-fish have been carried out by a variety of in situ and mapping methods. Benthic sampling techniques such as quadrats and transects have been used to quantify small reef features and their associations with reef-fish (Levin 1991, Fowler et al. 1992, Gratwicke \& Speight 2005). Recent mapping efforts have used aerial photography (Coyne et al. 2001), multi-beam mapping (Nasby-Lucas et al. 2002) and geographic information systems (GIS) (Stanbury \& Starr 1999) to map benthic landscapes in relation to fish abundance and distribution (Kendall et al. 2003, Friedlander et al. 2007). While small-scale studies may reveal details about the underlying patterns of biological mechanisms, different generalizations are likely to emerge at larger scales (Wiens 1989). For example, remote sensing techniques used for large-scale studies may suppress considerable ecological detail by lumping functional ecological classes into crude assemblages (Levin 1992). On the other hand, small-scale studies cannot be used to explain patterns at larger scales because different mechanisms may be acting to produce observed patterns (Levin 1992, Schneider et al. 1997). Thus, examination of fish abundance and distribution across a range of spatial scales will likely provide information pertinent to multiple ecological processes and, in turn, data useful for ecosystem-based management.

In the present study, we used a combination of the National Oceanic and Atmospheric Administration's (NOAA) hierarchical classification scheme for benthic habitats in Hawaii (Coyne et al. 2003), existing aerial photography and in situ biological and physical observations using SCUBA to develop a map of reef habitats previously identified as important to the life history of aquarium fish and other reef species. NOAA's classification scheme defined habitat types in a collapsible hierarchy ranging from broad categories of habitat structure (i.e. uncolonized volcanic rock/boulders, aggregate reef coral, rubble and others) to more detailed categories of biological substrate (i.e. emergent vegetation, algae, etc.). The present study builds on this scheme to develop a more detailed benthic habitat map that describes and georeferences reef habitats identified to be ecologically important to managed species in Hawaii. With the use of georeferenced in situ video transects, we described the physical structure and biological substrate of multiple habitat categories in relation to NOAA's aerial photography. The benthic habitat map we created describes both the distribution of large habitat features as well as small substrate features, such as solitary and reefbuilding coral types, rubble, boulder and sand.

Our overall objective is to develop a new method to examine the ontogenetic patterns of habitat use by reef-fish and provide information whereby the effectiveness of a well-studied MPA network can be evaluated relative to the distribution and abundance of habitat types at multiple spatial scales. In the present study we describe the development of the method and illustrate its usefulness using data on the yellow tang, a species which comprises the majority of the catch for the aquarium trade in West Hawaii (Walsh et al. 2004a). However, the method is also of broad use to a variety of reef species, which we will present elsewhere. In the present study, we specifically (1) develop a georeferenced habitat map which describes the abundance and distribution of habitats within 4 sites, (2) evaluate spatial patterns of abundance and distribution of individual life stages of yellow tangs in these sites, (3) evaluate the relationship between FRA effec- 
tiveness and the abundance and distribution of habitats and describe how our method can be used to design MPA networks and promote ecosystem-based management.

\section{MATERIALS AND METHODS}

Study sites. We examined 4 different MPAs (Fig. 1). Two of these sites were FRAs, Honokohau $\left(19^{\circ} 40.26^{\prime} \mathrm{N}, 156^{\circ} 01.82^{\prime} \mathrm{W}\right)$ and Anaehoomalu Bay $\left(19^{\circ} 57.17^{\prime} \mathrm{N}, 155^{\circ} 51.97^{\prime} \mathrm{W}\right)$, that have varied in their effectiveness to replenish aquarium reef-fish (Walsh et al. 2004b). FRA effectiveness (R) represents the change in density of targeted fish in FRAs relative to adjacent reference control sites. The 2 reference control sites, Wawaloli $\left(19^{\circ} 42.00^{\prime} \mathrm{N}, 1^{\circ} 6^{\circ} 02.99^{\prime} \mathrm{W}\right)$ and Puako $\left(19^{\circ} 58.19^{\prime} \mathrm{N}, 155^{\circ} 50.93^{\prime} \mathrm{W}\right)$, are MPAs where the collection of aquarium fish has been prohibited for more than 10 yr (Department of Land and Natural Resources 1996). These sites were the control sites used in the effectiveness measurement by Walsh et al. (2004b), but for the purpose of the present study are only used to illustrate the usefulness of our method in evaluating the spatial patterns of abundance and distribution of individual life stages of yellow tangs. $\mathrm{R}$ represents an index of effectiveness measured statistically as the change in the difference in fish density between each FRA and control site during baseline to post-baseline surveys (Walsh et al. 2004b). Although R measures the changes within the FRA as a percent of the baseline abundance relative to control sites, another measure of change in the FRAs is the absolute percent change in density of the baseline surveys relative to the postclosure surveys (Walsh et al. 2004b). Thus, both of these measures serve to determine how functional the FRAs are in replenishing targeted aquarium fish. The Honokohau FRA showed a $40 \%$ percent change in yellow tang density, but relative to its control site (Wawaloli) it showed an 18\% decrease in yellow tang. Both of these results were not statistically significant. On the other hand, Anaehoomalu has shown a statistically significant $79 \%$ change in yellow tang density and a $54 \%$ increase in yellow tang relative to its control site (Puako) (Walsh et al. 2004b).

Habitat map development. The development of a multi-scale benthic habitat map was based on aerial photographs of the island of Hawaii (Coyne et al. 2001), Light Detection and Ranging Technology (LIDAR) data (SHOALS LIDAR Bathymetry 2002) and in situ geographically referenced underwater video (UV) surveys (Fig. 2). NOAA's benthic habitat maps of the Main Hawaiian Islands define habitat types based on insular-shelf zones and structure of benthic communities greater than 1 acre in size (Coyne et al. 2003). The characterization of habitat types in the present study adds to the classification scheme developed by NOAA.

UV surveys: In situ benthic habitat data were obtained by conducting georeferenced UV surveys. The start positions of the transects were randomly generated along the delineated $25 \mathrm{~m}$ boundary of NOAA's maps using the random point generator extension in ArcView (Jenness 2005). An underwater scooter, mounted with an underwater video camera, compass and dive computer, was
Fig. 1. Study areas in the Island of Hawaii showing the location of 4 study sites 


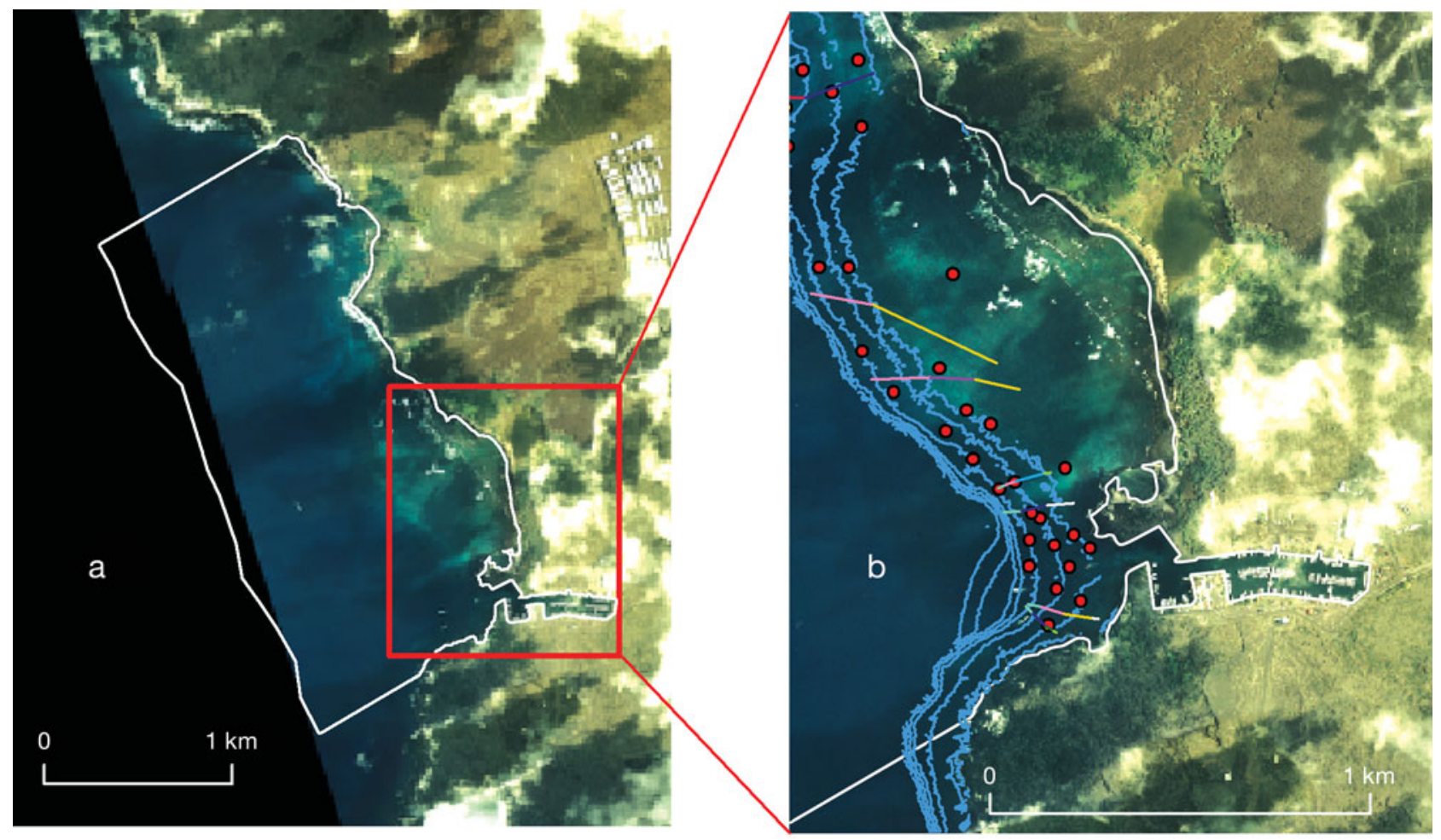

Fig. 2. Benthic habitat maps developed for Honokohau, Hawaii. Mapping was completed using (a) NOAA's aerial photographs, and (b) underwater video (UV) survey transects, bathymetry and randomly assigned habitat assessments (red circles)

used to run transects perpendicular to shore while recording the bottom with the camera. A total of 41 transects (Puako = 8, Anaehoomalu $=11$, Honokohau $=$ 10 and Wawaloli = 12) were run from a depth of 2 to $25 \mathrm{~m}$. The range of transect lengths and dive times was ca. 50 to $900 \mathrm{~m}$, and 15 to $35 \mathrm{~min}$, respectively. Geographic coordinates for all transects were obtained by placing a global positioning device (GPS) in a dry bag, connected via a float and dive flag to the diver's buoyancy compensation device (BCD) using a 100 m transect line. The diver was ca. $2 \mathrm{~m}$ off the bottom while recording the substrate, followed by the GPS at the surface. The GPS device was kept directly above the diver by adjusting the transect line attached to the diver's BCD. Before every dive, the GPS device was set to track the location of the diver. The time on the video camera was synchronized with the time on the GPS device before every dive, so that benthic data was linked to the geographic position. The geographic coordinates matching the time on the camera were used to determine the location and extent of changes in habitat type.

Video analysis and habitat mapping: A single observer (Ortiz) viewed the $5 \mathrm{~h}$ of video generated from the underwater transects. The videos were analyzed and transects subdivided into contiguous segments of unique habitat types. We defined habitat types based on 6 categories of physical substrate, based on the lithology and geomorphology of the seafloor, and 5 categories of biological substrate. Physical substrate categories were based on NOAA's benthic habitat classification and comprised B (colonized volcanic rock/boulder), A (aggregate reef), S (sand), $\mathrm{P}$ (pavement), T (scattered coral rock), U (unknown), and R (rubble) (Coyne et al. 2001). Biological substrate were based on previous UV surveys in West Hawaii (Tissot \& Hallacher 2003) and comprised C for the finger coral Porites compressa, L for the lobe coral Porites lobata, E for the cauliflower coral Pocillopora meandrina, $\mathrm{M}$ for mixed coral (denotes areas where the dominance of cauliflower, finger and lobe coral varied) and $\mathrm{u}$ for uncolonized. Habitat types were categorized using a 3-code system where the first letter denoted the primary physical substrate $(>50 \%)$ and the second and third letters denoted the primary ( $\geq 50 \%$ ) and secondary ( $>20 \%$ and $<50 \%$ ) biological substrate types, respectively (e.g. BEL represented at least $50 \%$ cover by boulders with at least $50 \%$ covered by cauliflower coral and at least $20 \%$ lobe coral).

Benthic habitat maps were then created using NOAA's habitat digitizing extension in ArcView 3.3 (Kendall et al. 2001) and ArcGIS 8.3 software. Using the location and classification of each video-transect within a site, bathymetric data and aerial photographs, borders were drawn around areas representing similar 
habitats. Thus, the benthic habitat map displays homogeneous areas of habitat types derived from the videotransect data. From here on, habitat type refers to those areas on the benthic habitat maps and not the video-transect data, unless specified. A minimum mapping unit (MMU) of $1045 \mathrm{~m}^{2}$ and a restricted mapping scale of 1:2500 was used. These settings allowed for mapping of features larger than the MMU selected and for digitization to occur at the same level of detail. Both the area of habitat types and percent area of the physical substrate categories at each site was determined using ArcGIS Xtools extension (ESRI 2002).

Accuracy of the benthic habitat map was quantified using an error matrix. The matrix is made up of rows and columns that represent each habitat type, with each cell representing the total sites sampled for that particular habitat type. A total of 90 sites were randomly sampled within mapped habitat types. At each sampling site, a visual assessment of the habitat type was made. The mapped habitat type was then compared with that of the actual habitat type from field observations. Accuracy of the benthic habitat map is equivalent to the probability of correctly determining the habitat type present. For example, accuracy was calculated as the probability of classifying an area as uncolonized boulders in the map when it was also uncolonized boulder from field observations.

Bathymetry: Airborne Bathymetric Lidar surveys of Hawaii were conducted in 2000 using LIDAR by the Airborne Lidar Bathymetry Technical Center of Expertise (SHOALS LIDAR Bathymetry 2002). These surveys allowed rapid and accurate measurements of highresolution bathymetric data. Depth data for our study sites was downloaded and displayed as $5 \mathrm{~m}$ grids using ArcGIS 8.3 (ESRI 2002) and used to describe depth ranges for habitat types in the present study (Table 1).
Fish and benthic surveys. Fish abundance at each location was assessed between May and July 2005 using circular plot counts. Surveys were done within each habitat type at each site. A SCUBA diver recorded the abundance and length of fish seen within 115 randomly selected $5.0 \mathrm{~m}$ radius circular plots (78 $\mathrm{m}^{2}$ plot area). The circular plot method was chosen because it easily randomized sample locations within a given depth strata, increased the potential replication in a given survey period due to its quick deployment and thus allowed a short period of time in a survey area, thereby decreasing bias estimates due to net movement of reef-fish (Watson et al. 1995). In order to avoid bias and prevent over- and under-counting of individuals, fish that were unlikely to remain in the area (i.e. mobile fishes) were tabulated first and then ignored. The diver periodically calibrated estimates of the sample radius with a $10 \mathrm{~m}$ transect line marking the circumference of the circle. One complete rotation was made for each plot, and size estimates of fish were verified using a cm-scaled underwater slate. Fish were categorized as recruits, juveniles or adults based on body size and/or coloration. For the purpose of analysis, recruits were generally individuals $<5 \mathrm{~cm}$ in size. Juveniles refer to individuals of 5 to $14 \mathrm{~cm}$, and adults refer to individuals $>14 \mathrm{~cm}$ in length.

Depth, rugosity and percent substrate cover were estimated within each plot using a $10 \mathrm{~m}$ transect line positioned parallel to shore. Depth was recorded at the center, and at $90^{\circ}$ intervals around the edges of the circular plot. The 5 depth readings produced a mean depth for each circular plot. Rugosity, or the surface relief of the reef, was measured using a fiberglass tape measure extended along and following the contour of the transect. A ratio of the length of the tape compared to the length of the transect was used as an index of rugosity.

Table 1. Habitat types and classification scheme based on the present study: $\mathrm{A}=$ aggregate reef; $\mathrm{M}=$ mixed; $\mathrm{B}=\mathrm{boulders}$; $\mathrm{P}=$ pavement $\mathrm{E}=$ cauliflower coral $($ Pocillopora meandrina $) ; \mathrm{L}=$ lobe coral $($ Porites lobata $) ; \mathrm{C}=$ finger coral $(P$. compressa $) ;$ $\mathrm{u}=$ uncolonized $\mathrm{T}=$ scattered coral rock; $\mathrm{R}=$ reef rubble; $\mathrm{S}=$ sand

\begin{tabular}{|lllr|}
\hline Habitat code & Reef zone & Description & Depth range (m) \\
\hline $\mathrm{Bu}$ & Reef flat & Uncolonized boulders & $0-3$ \\
$\mathrm{Pu}$ & Reef flat & Uncolonized pavement & $0-3$ \\
$\mathrm{PEL}$ & Reef flat & Colonized pavement with cauliflower and lobe coral cover & $2-8$ \\
$\mathrm{Tu}$ & Reef flat & Scattered coral rock & $4-5$ \\
$\mathrm{BEL}$ & Boulder & Colonized boulders with cauliflower and lobe coral cover & $3-11$ \\
$\mathrm{BLL}$ & Boulder & Colonized boulders with lobe coral cover & $5-20$ \\
$\mathrm{BLE}$ & Boulder & Colonized boulders with lobe and cauliflower coral cover & $5-25$ \\
$\mathrm{AEL}$ & Reef slope & Aggregate reef with cauliflower and lobe coral cover & $5-10$ \\
$\mathrm{ALC}$ & Reef slope & Aggregate reef with lobe and finger coral cover & $7-10$ \\
$\mathrm{ALE}$ & Reef slope & Aggregate reef with lobe and cauliflower coral cover & $5-24$ \\
$\mathrm{AM}$ & Reef slope & Aggregate reef with mixed cover & $8-30$ \\
$\mathrm{ACL}$ & Reef slope & Aggregate reef with finger and lobe coral cover & $8-30$ \\
$\mathrm{Ru}$ & Rubble & Uncolonized rubble & $20-40$ \\
$\mathrm{~S}$ & All zones & Sand & $0-40$ \\
\hline
\end{tabular}


An underwater digital camera was used to take 10 photoquadrats along each transect, $1 \mathrm{~m}$ above the substrate. Each of 1150 images was projected onto a rectangular grid using Photogrid software (Bird 2003). Percent cover for substrate types was quantified under 20 random points on each grid. These substrate types included finger coral, lobe coral, cauliflower coral, finger coral holes/crevices, coralline crustose, sand, turf algae, turf algae on boulders and turf algae on rubble. Percentage cover of substrates at each site was calculated as the percentage of the points on each transect occupied by the same substrate type within each site.

Data analysis. Detrended Correspondence Analysis (DCA) was used to describe associations between habitat circular plot data from the benthic habitat map and quadrats along transects. A matrix of plot samples classified by habitat type (115 plots) and quantified by percent cover of substrate (1150 quadrats) was used in the analysis. DCA produces a graphical ordination that shows the similarity between observations (habitat types) and variables (substrates) derived from a frequency table (SAS Institute 2000). Observations that correspond in sampling space are close together in ordination, while the strength of the relationship between observations and variables is indicated by the direction of the points from the plot's origin (Pimentel 1979).

Percent area of physical substrate (aggregate reef, rock/boulder, pavement, rubble and sand) from the benthic habitat map and percent cover of substrate (finger coral, lobe coral, cauliflower coral, finger coral holes/crevices, coralline crustose, sand, turf algae, turf algae on boulders and turf algae on rubble) from the quadrat data were used to describe dominant substrata among sites. Percent area of physical substrate was calculated using ArcGIS Xtools extension (ESRI 2002), while the percent cover of substrates was calculated as the percentage of the points on each transect occupied by the same substrate type within each site.

A Canonical Correspondence Analysis (CCA) was carried out to describe patterns in the distribution of yellow tang life stages among habitat types and how they relate to a set of environmental variables. A matrix of circular plot samples classified by habitat type and abundance of yellow tangs (density of recruit, juvenile and adult within each plot) and environmental variables (depth, rugosity, percent cover of finger, cauliflower and lobe coral and turf algae within each plot) was used in the analysis. CCA produces a graphical ordination that detects the patterns of variation in life history stages that can best be explained by environmental variables (Ter Braak 1986). Thus, the location of individual circular plots (habitat type scores) in the multivariate space indicate how the abundance of yellow tang life stages at each habitat type varied in relation to the combination of environmental variables, while the location of yellow tang life stages (life stages scores) indicate the mean values of the response curves (abundance variations) of yellow tangs on the CCA axes (Ter Braak 1986). In order to better interpret the results of the CCA, the 14 individual habitat types were condensed into 3 broad but distinct habitat categories based on their physical and biological similarities: deep aggregate coral-rich and sandy rubble habitats (ACL, ALC, AM, Ru and S), mid-depth aggregate reef and boulder habitats (ALE, AEL, BLL and BLE) and shallow turf-rich boulder habitats (BEL, PEL, Bu, Pu and $\mathrm{Tu}$ ).

Differences in the density of each life stage among habitat categories and sites were compared using a Kruskal-Wallis test or an ANOVA with Dunn's test for unplanned multiple comparisons depending on whether they met the assumptions for ANOVA (Zar 1984). Bonferroni adjustments were conducted to ameliorate concerns over multiple statistical testing (Holm 1979).

In order to evaluate the relationship between FRA effectiveness and the abundance and distribution of habitats, we compared population size estimates of recruit, juvenile and adult yellow tangs relative to percent area of habitat categories at 1 FRA showing significant increases and 1 FRA showing a decrease in yellow tang densities. Population size estimates were calculated by multiplying the mean density of each life stage by the reef area derived from the habitat map (i.e. reef structure from shore to a depth of $25 \mathrm{~m}$ ) and dividing it by the reef length (i.e. length of shoreline) at each site (Table 2). This adjustment was done to account for the different shoreline lengths and reef structure from shore to depth. The percent area of habitat categories represents the total percent area of habitat types belonging to each category. Both the reef area and length were calculated using ArcGIS 8.3 (ESRI 2002). Habitats with low coverage area and exceeding $25 \mathrm{~m}$ depths were not sampled and excluded from the analysis owing to fewer sightings of yellow tang and extent of habitat map, respectively. Although some habitats were not sampled, we were able to account for more than $70 \%$ of the reef area at each site.

\section{RESULTS}

\section{Habitat classification}

Using an error matrix the overall accuracy of the benthic habitat map was $93 \%$. Patchy boulder areas with low to high coral cover and aggregations of finger and lobe coral located in areas of abrupt change were less accurate (83\%), in part due to the patchy nature of these habitats. 
Table 2. Area coverage, reef length, sampling allocation, depth and rugosity for habitat types at each study site. SE is standard error, $\mathrm{N}$ is the total number of surveys, and MR is the mean rugosity per habitat at each site. Habitat types are ordered from deep to shallow depths at each site

\begin{tabular}{|c|c|c|c|c|c|c|c|}
\hline \multirow[t]{2}{*}{ Site } & \multirow{2}{*}{$\begin{array}{l}\text { Habitat } \\
\text { code }\end{array}$} & \multirow{2}{*}{$\begin{array}{c}\text { Area coverage (ha) } \\
{[\% \text { area }]}\end{array}$} & \multirow{2}{*}{$\begin{array}{c}\text { Reef length } \\
(\mathrm{km})\end{array}$} & \multirow[t]{2}{*}{$\mathrm{N}$} & \multirow[t]{2}{*}{$\mathrm{MR}$} & \multicolumn{2}{|c|}{ Mean depth (m) } \\
\hline & & & & & & Depth & SE \\
\hline \multirow[t]{9}{*}{ Puako } & $\mathrm{S}$ & $0.99[<1]$ & & 0 & - & - & - \\
\hline & $\mathrm{Ru}$ & $2.10[2]$ & & 0 & - & - & - \\
\hline & $\mathrm{ACL}$ & 21.9 [21] & & 12 & 1.37 & 8.96 & 2.05 \\
\hline & AEL & $9.06[9]$ & & 3 & 1.22 & 8.73 & 0.77 \\
\hline & BEL & $16.3[16]$ & & 8 & 1.22 & 3.60 & 1.52 \\
\hline & $\mathrm{Tu}$ & $2.73[3]$ & & 0 & - & - & - \\
\hline & PEL & 2.67 [3] & & 0 & - & - & - \\
\hline & $\mathrm{Bu}$ & 48.5 [46] & & 4 & 1.25 & 1.88 & 0.39 \\
\hline & Total & 104 & 3.30 & 27 & & & \\
\hline \multirow[t]{10}{*}{ Anaehoomalu } & $\mathrm{S}$ & 390 [33] & & 2 & 1.16 & 11.40 & 2.60 \\
\hline & $\mathrm{ACL}$ & 157 [13] & & 9 & 1.24 & 9.89 & 2.19 \\
\hline & AM & $58.3[5]$ & & 8 & 1.18 & 8.68 & 2.20 \\
\hline & ALE & 214 [18] & & 5 & 1.31 & 8.53 & 2.45 \\
\hline & ALC & $1.97[<1]$ & & 0 & - & - & - \\
\hline & AEL & $0.01[<1]$ & & 0 & - & - & - \\
\hline & BLE & 206 [17] & & 0 & - & - & - \\
\hline & BEL & $7.00[<1]$ & & 6 & 1.62 & 3.62 & 1.03 \\
\hline & $\mathrm{Bu}$ & 156 [13] & & 0 & - & - & - \\
\hline & Total & 1190 & 6.80 & 30 & & & \\
\hline \multirow[t]{7}{*}{ Wawaloli } & $\mathrm{Ru}$ & $2.22[6]$ & & 2 & 1.14 & 15.63 & 1.05 \\
\hline & $\mathrm{AM}$ & $0.46[1]$ & & 3 & 1.24 & 14.39 & 1.47 \\
\hline & BEL & $17.7[49]$ & & 10 & 1.20 & 11.96 & 3.02 \\
\hline & BLE & $2.58[7]$ & & 3 & 1.15 & 10.73 & 1.47 \\
\hline & PEL & $10.1[28]$ & & 5 & 1.16 & 4.23 & 1.57 \\
\hline & $\mathrm{Pu}$ & 3.13 [9] & & 0 & - & - & - \\
\hline & Total & 36.2 & 2.00 & 23 & & & \\
\hline \multirow[t]{9}{*}{ Honokohau } & $\mathrm{S}$ & 2.12 [2] & & 0 & - & - & - \\
\hline & $\mathrm{Ru}$ & $2.84[2]$ & & 0 & - & - & - \\
\hline & $\mathrm{AM}$ & 2.09 [2] & & 8 & 1.31 & 12.19 & 1.25 \\
\hline & BLL & 28.9 [26] & & 11 & 1.62 & 8.76 & 1.30 \\
\hline & BEL & $12.0[11]$ & & 8 & 1.82 & 6.71 & 1.27 \\
\hline & PEL & 32.3 [29] & & 8 & 1.51 & 5.02 & 1.21 \\
\hline & $\mathrm{Pu}$ & 31.8 [28] & & 0 & - & - & - \\
\hline & $\mathrm{Bu}$ & $0.55[<1]$ & & 0 & - & - & - \\
\hline & Total & 112 & 2.70 & 35 & & & \\
\hline
\end{tabular}

The DCA revealed strong correlations between the visual assessment of habitat types and the percent cover of substrates among all sites (Fig. 3). The percent variation explained by the canonical dimensions was 36 and $23 \%$ for the first and second axes, respectively. Aggregations of finger and lobe coral habitats (AM and ACL) were associated with high cover of lobe and finger coral and finger coral holes/crevices substrate. Aggregate and colonized boulder with high to low cauliflower and lobe coral cover habitats (ALE, AEL, BLL, BLE, BEL, PEL and Bu) were associated with turf algae on boulders, coralline crustose, cauliflower coral and lobe coral substrates. Sand and rubble habitats ( $\mathrm{S}$ and $\mathrm{Ru}$ ) were associated with sand and turf algae on rubble substrates. These associations demonstrate that the benthic habitat map was largely consistent with percent cover data measured using quadrats.

\section{Description of reef habitats}

A total of 14 habitat types occurred among all study sites (Table 1). The abundance and distribution of habitat types, depths and rugosity varied among sites (Table 2, Fig. 4). At Honokohau, uncolonized boulder $\mathrm{Bu}$ ) and pavement (PEL and Pu) habitats were dominant in shallow depths while colonized boulder with lobe and cauliflower coral cover habitats (BLL and BEL) dominated deeper depths. Wawaloli was dominated by colonized boulder and pavement with cauliflower and lobe coral cover habitats (BEL and PEL) at both shallow and deeper depths. Puako was dominated by uncolonized boulders $(\mathrm{Bu})$ and boulder with cauliflower and lobe coral cover habitats (BEL) at shallow depths, while aggregate reef with finger and lobe coral habitats (ACL) were dominant at deeper depths. Anaehoomalu was dominated by uncolonized boulder 


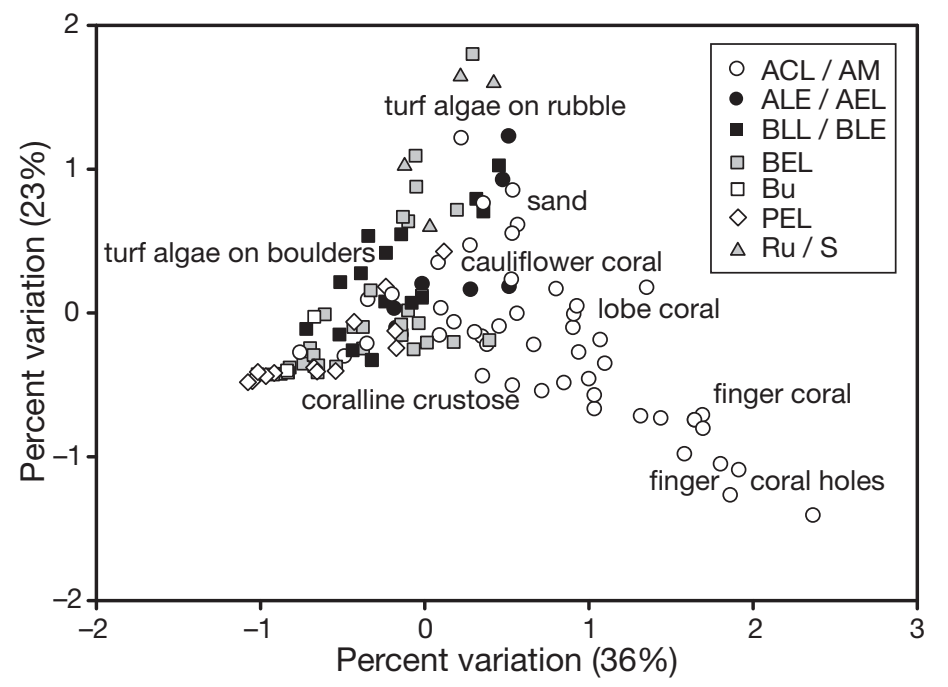

Fig. 3. Detrended Correspondence Analysis (DCA) of the associations between habitat types derived from benthic habitat maps and substrate cover derived from quadrat data among 4 study sites. Sampling locations (circular plots) were classified by habitat type. Quadrat data included percent cover of substrates (finger coral, lobe coral, finger coral holes/crevices, cauliflower coral, coralline crustose, turf algae and sand) within circular plots
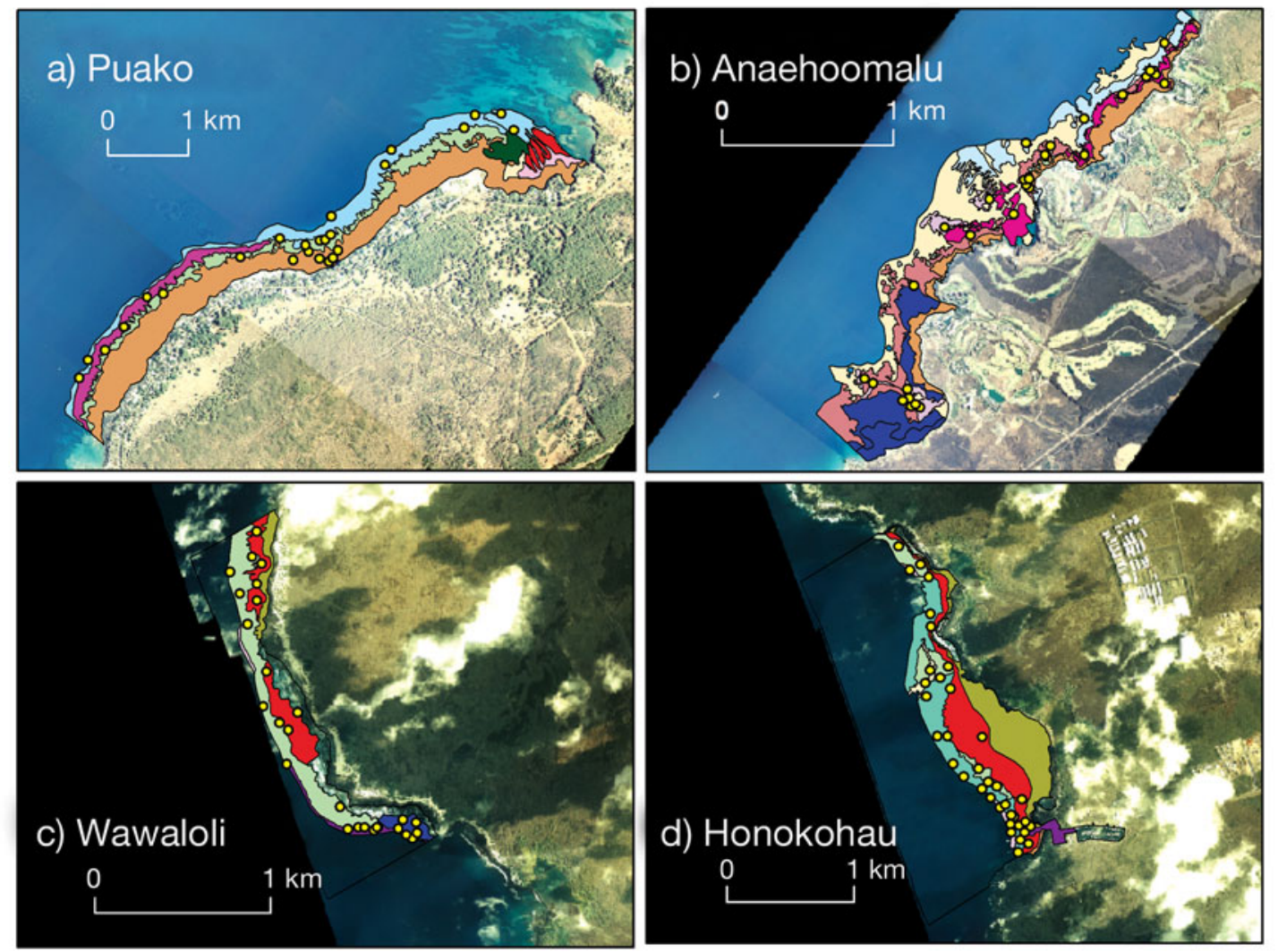

\section{Aggregate Reef/Mixed}

Aggregate Reef/Finger-Lobe coral

\section{Aggregate Reef/Lobe-Finger coral}

Aggregate Reef/Lobe-Cauliflower coral

Aggregate Reef/Cauliflower-Lobe coral
Colonized Boulder/Lobe-Lobe coral

Colonized Boulder/Lobe-Cauliflower coral

Colonized Boulder/Cauliflower-Lobe coral

Uncolonized Boulder

Colonized Pavement/Cauliflower-Lobe coral

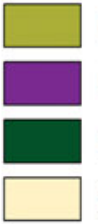

Uncolonized Pavement Uncolonized Rubble

Scattered Coral rock Sand

- Plots

Fig. 4. Habitat maps of study sites (a) Puako, (b) Anaehoomalu, (c) Wawaloli and (d) Honokohau in Hawaii created using aerial photography and in situ video transects. Yellow circles indicate location of circular plots 
habitats $(\mathrm{Bu})$ and colonized boulder with lobe and cauliflower coral cover habitats (BLE) at shallow depths followed by aggregate reef with finger, lobe and cauliflower coral (ACL and ALE) at deeper depths. The central reef area of Anaehoomalu was heavily fragmented and isolated by sand (S). Uncolonized rubble $(\mathrm{Ru})$ habitats were generally found at deeper depths at most sites. Rubble habitats in Wawaloli had the lowest rugosity (1.14), while boulder habitats in Honokohau and Anaehoomalu had the highest rugosity $(>1.62)$ among all sites. Rugosity of aggregate reef habitats varied greatly among sites (1.18 to 1.37$)$ (Table 2).

Percent cover of substrata varied among sites (Fig. 5). Overall, of the 4 sites mapped, Honokohau and Wawaloli were predominantly composed of pavement and boulder substrate, while Puako and Anaehoomalu were predominantly boulder and aggregate reef, and some had a mixture of sand and rubble substrates (Fig. 5). Puako was dominated mostly by finger coral $(27 \%)$, turf algae $(14 \%)$ and lobe coral $(11 \%)$, while finger coral $(27 \%)$, turf algae $(15 \%)$ and sand $(13 \%)$ were the dominant substrata in Anaehoomalu. Honokohau and Wawaloli were dominated by turf algae (24 and $38 \%$, respectively), finger coral (20 and $11 \%$, respectively) and coralline crustose (15 and $11 \%$, respectively). Although finger coral was abundant in Honokohau and Wawaloli, distribution of this substrate was largely fragmented and distributed along patches of reef overlaying boulder and pavement substrata (D. M. Ortiz pers. obs.).

\section{Habitat use}

A total of 115 circular plots (Honokohau = 34 , Puako $=27$, Wawaloli $=24$ and Anaehoomalu $=30$ ) were surveyed for fish (Fig. 4). Overall, new recruits and juvenile yellow tangs were most abundant on both deep aggregate coral-rich and sandy rubble and middepth aggregate reef and boulder habitats (AM, ACL, ALC, ALE, AEL, BLL, BLE, Ru and S), while adults were most abundant at the shallow turf-rich boulder habitats on the reef flat (BEL, PEL, Bu, Pu and Tu) (Figs. 6 \& 7).

CCA revealed significant associations among the sizes of tang, habitat types and environmental variables at each site (Fig. 6) (Chi-square; all axes $\mathrm{p}<0.001$ ). The percent variation explained by the canonical dimensions was 96 and $4 \%$ for the first and second axes, respectively. The abundance of recruits and juveniles was highest within deep aggregate coral-rich and sandy rubble and mid-depth reef and boulder habitats. Adult abundance was higher within the shallow turf-rich boulder habitat (Figs. $6 \& 7$ ).

However, these patterns varied among sites. At Honokohau and Wawaloli recruits and juveniles were distributed along mid-depth aggregate reef and boulder and shallow turf-rich boulder habitats having patchy areas of finger and cauliflower coral substrate (Figs. $6 \& 7 \mathrm{c}, \mathrm{d}$ ), while Puako and Anaehoomalu sites had recruit and juveniles associating with deep aggregate coral-rich and sandy rubble and mid-depth aggregate reef and boulder habitats (Fig. 7a,b). Adults were strongly associated with the shallow turf-rich boulder habitat, but were also found across all habitats to some extent (Figs. $6 \&$ 7).
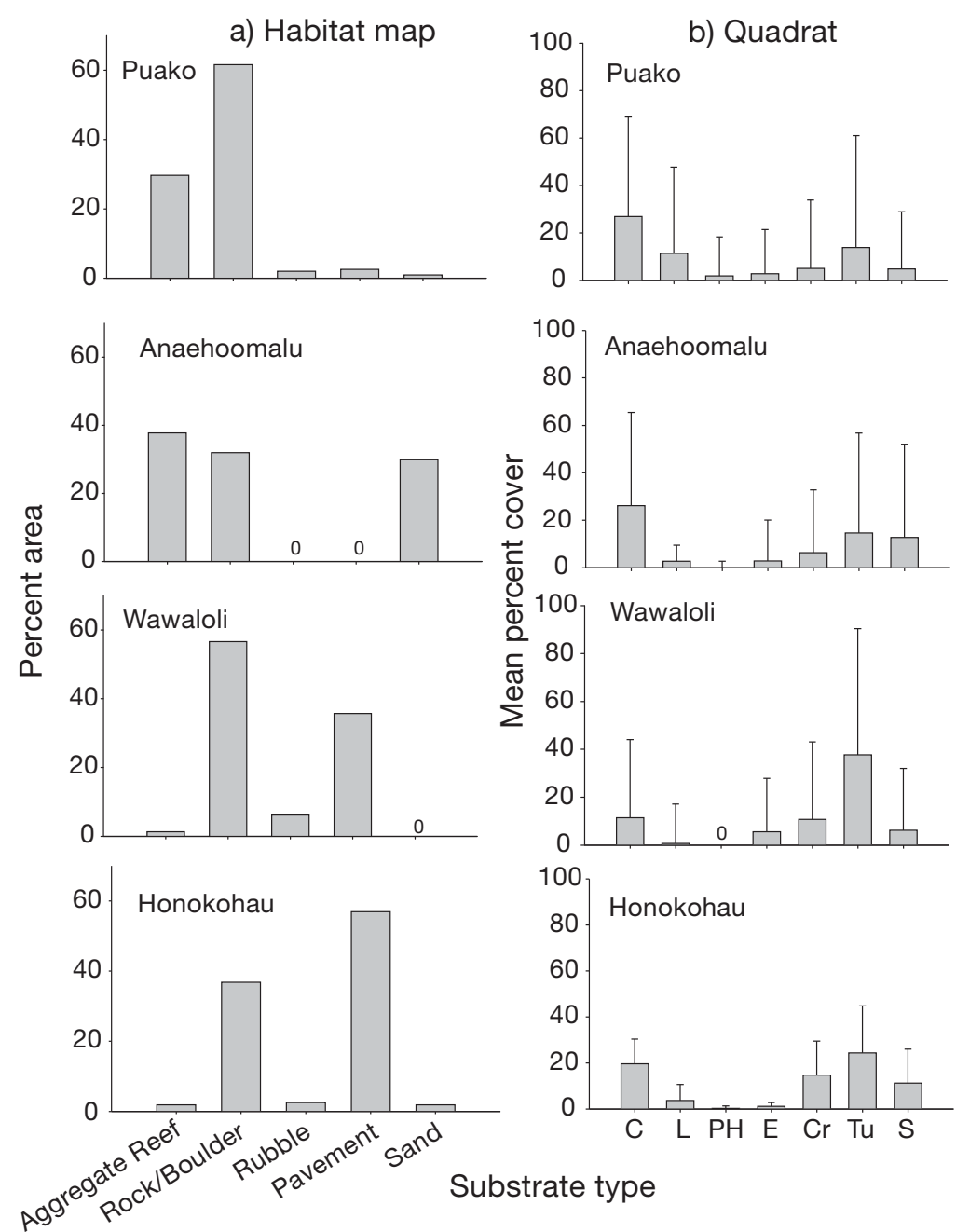

Fig. 5. (a) Percent area of physical substrate for each site derived from benthic habitat maps. (b) Percent cover of the 7 most abundant substrates derived from quadrat data at each site: $C$ (finger coral), L (lobe coral), PH (finger coral holes/crevices), E (cauliflower coral), $\mathrm{Cr}$ (coralline crustose), Tu (turf algae) and S (sand) 
O Deep aggregate coral-rich and sandy rubble habitat (ACL, ALC, AM, Ru, S)

- Mid-depth aggregate reef and boulder habitat (ALE, AEL, BLL, BLE)

$\triangle$ Shallow turf-rich boulder habitat (BEL, PEL, Bu, Pu, Tu)

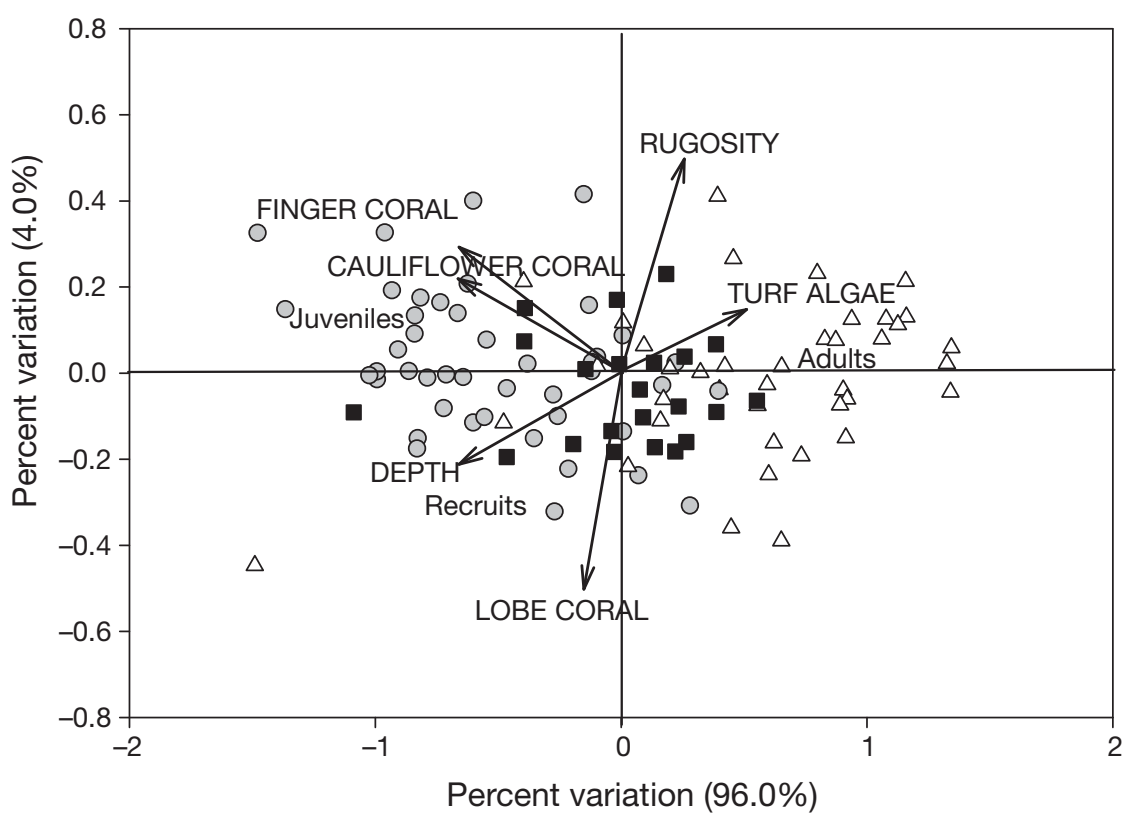

Fig. 6. Canonical Correspondence Analysis (CCA) of the associations of yellow tang recruits, juveniles and adults to habitat types and environmental variables at all study sites. Sampling locations (circular plots) were classified by habitat type from benthic habitat maps. Quadrat data included yellow tang abundance (recruit, juvenile and adult densities) and environmental variables (depth, rugosity, percent cover of finger, cauliflower and lobe coral and turf algae cover) within circular plots. Habitat types were grouped into 3 distinct habitat categories in order to aid in the interpretation of the data (see text). Habitat types and life stages are represented by points and environmental variables by arrows, whereby the length of the arrow is a measure of how much the distribution of each life stage differs along environmental variables (Ter Braak 1986).

\section{Environmental variables influencing abundance and distribution of yellow tang}

Depth, rugosity and percent cover of turf algae and finger, lobe and cauliflower coral explained the major variation among yellow tang recruits, juveniles and adults (Fig. 6). Depth, accounting for $49 \%$ of the variance, decreased along the first axis. Percent cover of turf algae, accounting for $86 \%$ of the variance, increased along the second axis. Percent cover of finger, cauliflower and lobe coral and rugosity, accounting for 86, 40, 67 and $60 \%$ of the variance, respectively, increased along the second axis. Thus, recruits and juveniles were mainly found in deep habitats with the highest percentage of finger, cauliflower and lobe coral cover, with recruits also found in deeper sandy rubble habitats, while adults occurred in shallow complex habitats with the highest percentage of turf algae.

\section{Fish density among habitats and sites}

The density of each life stage was significantly different among habitat categories. Recruits were significantly different among habitats $(H=20.9$, p $<0.001)$, being significantly higher in deep aggregate coral-rich and sandy rubble habitat averaging $5.7( \pm 7.7 \mathrm{SD})$ recruits per circular plot $\left(78 \mathrm{~m}^{2}\right)$, compared to shallow turfrich and boulder habitat which averaged only $1.2( \pm 3.9 \mathrm{SD})$ recruits. Significant differences among habitats were detected for juveniles $(H=30.7$, $p<0.001)$. Juvenile densities were significantly higher in deep aggregate coral-rich and sandy rubble habitat, averaging 7.7 ( $\pm 7.6 \mathrm{SD}$ ) juveniles, compared to both mid-depth aggregate reef and boulder and shallow turf-rich boulder habitats averaging 3.2 $( \pm 5.5 \mathrm{SD})$ and $0.5 \quad( \pm 1.4 \mathrm{SD})$ juveniles, respectively. Adults differed significantly among habitats $(H=28.2, \mathrm{p}<0.000)$. Adults were significantly higher in shallow turf-rich boulder habitats, averaging $13.4( \pm 18.6 \mathrm{SD})$ adults, compared to deep aggregate coral-rich and sandy rubble habitat, averaging only $3.0 \quad( \pm 5.8 \quad \mathrm{SD})$ adults. Variation in the mean density of recruit, juvenile and adult yellow tang among sites was not significantly different.

\section{Population size, habitat and FRA effectiveness}

The estimated population size of yellow tangs in each size-class varied among sites (Table 3). Overall, recruits, juveniles and adults were more abundant in Anaehoomalu and less abundant in Wawaloli. The Anaehoomalu FRA, with significant increases in yellow tang densities and the greatest abundance of deep aggregate coral-rich and sandy rubble and mid-depth aggregate reef and boulder habitats had the highest number of recruits and juveniles, while the Honokohau FRA, with a decrease in yellow tang densities and lower abundance of these habitats, had lower numbers of recruit and juveniles (Table 3). In addition, Honokohau, with a higher abundance of the shallow turf-rich boulder habitat, had a lower density of adults compared to Anaehoomalu. Adults were more abundant on those sites with lower shallow turf-rich boulder habitat (Puako and Anaehoomalu) compared to those that had more than $68 \%$ 

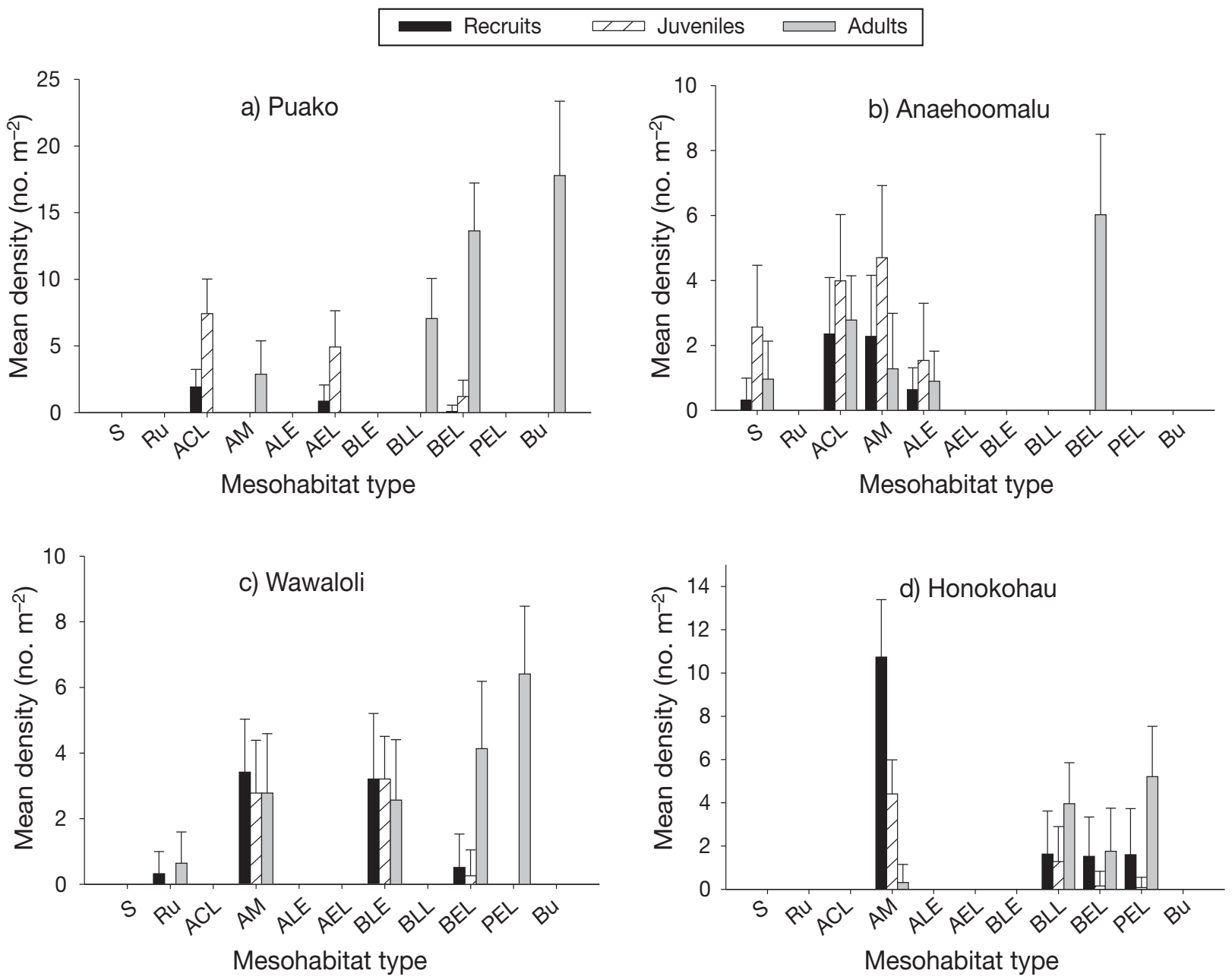

Fig. 7. Mean density ( $\pm 1 \mathrm{SE})$ of recruits, juveniles and adults of yellow tangs along habitats at each study site: (a) Puako, (b) Anaehoomalu, (c) Wawaloli and (d) Honokohau. Sites are ordered from north to south (a to d). Habitats are ordered from deep to shallow depths (left to right)

Table 3. Comparison of management regime, percent area of habitat categories among sites and population size (no. of ind. $\mathrm{km}^{-1}$ rounded to the nearest 1000) of recruits, juvenile and adult yellow tang at each study site. Habitat categories are coded as followed: (C1) deep aggregate coral-rich and sandy rubble habitat (ACL, ALC, AM, Ru and S), (C2) mid-depth aggregate reef and boulder habitat (ALE, AEL, BLL and BLE) and (C3) shallow turf-rich boulder habitat (BEL, PEL, Bu, Pu and Tu). Numbers in bold indicate highest percent area of habitat category and greater density of yellow tangs among sites. Numbers in parentheses indicate SE. Population size estimates were calculated by first multiplying the average density (no. $\mathrm{m}^{-2}$ ) of recruits, juveniles and adults per habitat type at each site by the area of the corresponding habitat type (in $\mathrm{m}^{2}$ ). Overall recruit, juvenile and adult estimates per habitat type per site were summed to obtain the total number of individuals of each life stage per site. Finally, the total number of individuals per life stage per site was divided by the length of the reef (in $\mathrm{km}$ ) at each site to obtain the population size estimates (no. $\mathrm{km}^{-1}$ ) listed

\begin{tabular}{|lcccc|}
\hline $\begin{array}{l}\text { Habitat categories } \\
\text { Management }\end{array}$ & $\begin{array}{c}\text { Puako } \\
\text { MPA }\end{array}$ & $\begin{array}{c}\text { Anaehoomalu } \\
\text { FRA }\end{array}$ & $\begin{array}{c}\text { Wawaloli } \\
\text { MPA }\end{array}$ & $\begin{array}{c}\text { Honokohau } \\
\text { FRA }\end{array}$ \\
\hline C1 & 23 & $\mathbf{5 2}$ & 7 & 6 \\
C2 & 9 & 35 & 7 & $\mathbf{8 6}$ \\
C3 & $\mathbf{6 8}$ & 13 & $1000(17000)$ & $\mathbf{6 8}$ \\
Recruits & $3000(20000)$ & $21000(112000)$ & $1000(12000)$ & $5000(80000)$ \\
Juveniles & $13000(43000)$ & $67000(231000)$ & $13000(45000)$ & $22000(81000)$ \\
Adults & $73000(176000)$ & $36000(154000)$ & & $(44000)$ \\
\hline
\end{tabular}


of these habitats (Honokohau and Wawaloli). Juvenile numbers were highest on those sites dominated by the deep aggregate coral-rich and sandy rubble habitat (Puako and Anaehoomalu). Recruits were more abundant in Anaehoomalu, with more than $52 \%$ of the deep aggregate coral-rich and sandy rubble habitat, followed by Honokohau, with less than $6 \%$ of this habitat. However, recruit numbers were 3 times higher in Honokohau than in Puako, which has $23 \%$ deep aggregate coral-rich and sandy rubble habitat (Table 3).

Reef area and the number of yellow tang in each size-class varied among sites (Fig. 8). Anaehoomalu had the largest reef area and the greatest number of recruits, juveniles and adults. Wawaloli had the smallest reef area and fewest numbers of recruits, juveniles and adults. Honokohau, with the second largest reef, had a greater number of recruits than Puako, while Puako, with the third largest reef area, had a greater number of juveniles and adults than Honokohau.

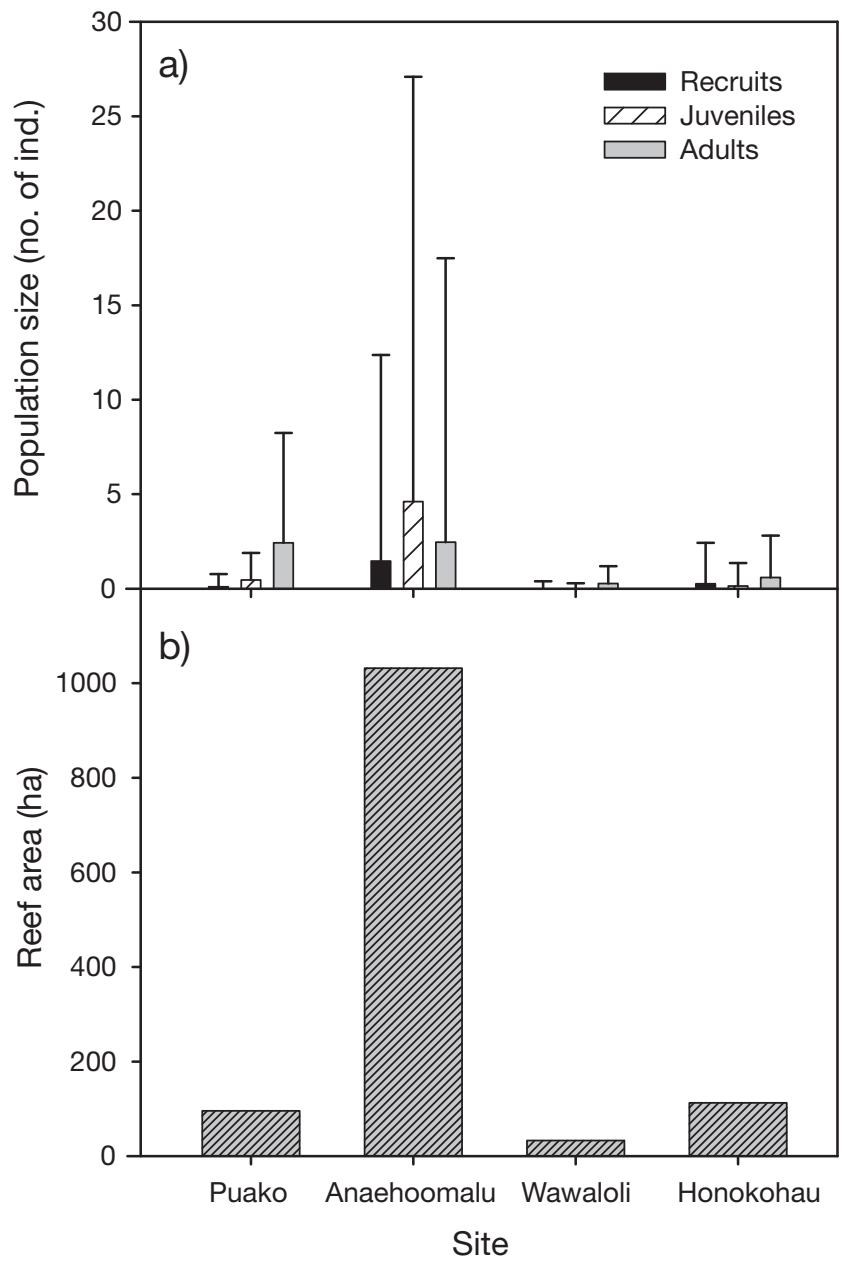

Fig. 8. (a) Estimated population sizes of yellow tang life stages and (b) reef area at each study site

\section{DISCUSSION}

\section{Habitat mapping}

A combination of remotely sensed data and in situ benthic sampling has provided numerous advantages in examining fish-habitat associations (Christensen et al. 2003, Friedlander et al. 2003, 2007), detecting habitat changes (Parsons et al. 2004) and assessing fish stocks (Nasby-Lucas et al. 2002). This integration of methods provided a useful quantitative approach for the description of coral reef habitats and the examination of ontogenetic patterns of habitat use by a reeffish, the yellow tang. Our findings showed a strong correlation between the benthic habitat maps and substrate cover, and ground-truthing confirms that the maps produced from this method can provide an accurate representation of the spatial variation of reef habitats and fish distributions.

Most studies examining fish-habitat associations have relied on transects and quadrats placed along reef zones or many benthic classifications such as sandy bottom, rubble or rocky/boulder habitat (Fowler et al. 1992, Green 1996, Aburto-Oropeza \& Balaart 2001, Nanami \& Nishihira 2002) and patch reefs (Depcznski \& Bellwood 2004). More recent methods have used aerial photography (Coyne et al. 2001), acoustic devices (Armstrong et al. 2006) and GIS (Stanbury \& Starr 1999) to map benthic landscapes. Fishhabitat association studied at the quadrat level, although informative, can fail to detect habitat use patterns at the landscape level by not including the mosaic and spatial arrangement of reef habitats important to reef-fish. For example, Parsons et al. (2004) found that without benthic habitat mapping, significant changes in benthic community structure would have not been detected with the use of traditional sampling methods (i.e. quadrats and transects). Nevertheless, the use of transects and quadrats is still an efficient way to carry out long-term studies and test specific hypotheses without requiring expensive technology and/or training.

Mapping efforts can be time consuming and costly, often requiring the use of expensive equipment and intensive sampling to validate the mapping effort. Our approach presents several advantages. First, our methods are relatively simple and present an inexpensive way to map and examine benthic landscapes in relation to reef- fish abundance, providing, of course, that aerial photographs are available. Second, the method does not require extensive training and equipment. Third, it can describe the spatial arrangement, distribution and abundance of reef habitats at multiple spatial scales. Fourth, population and community ecology data from a wide range of habitat types can be studied 
and applied to future management efforts. Fifth, the methodology here can be adapted for other regions and used to design and designate future MPA sites.

\section{Ontogenetic habitat shifts}

In the present study, the development of a habitat map allowed an examination of ontogenetic patterns of habitat use by a reef-fish. Reef-fish often settle in nursery areas (i.e. seagrass) or specific coral habitats (i.e. Porites sp.) and subsequently migrate to on-reef adult habitats in order to meet their changing needs (i.e. predator avoidance, reproduction and growth) as they mature (Beets \& Hixon 1994, Green 1996, Dahlgren \& Eggleston 2000). For example, within the vicinity of Lee Stocking Island, Bahamas, early juvenile Nassau grouper exhibit an ontogenetic movement from macroalgal clumps to patch reef habitats after settlement (Eggleston 1995). The present findings indicate that yellow tang exhibit an ontogenetic habitat shift from deeper aggregations of coral-rich habitats as recruits and juveniles to shallow turf-rich boulder habitats as they mature, a pattern previously described by Walsh (1985). Recruits $(\leq 5 \mathrm{~cm})$ and juveniles ( $>5$ and $<14.0 \mathrm{~cm}$ ) showed strong patterns of habitat selection among sites. The abundance of these early life stages is known to have a strong correlation with finger coral substrate (Walsh et al. 2004b, Fig. 6). Therefore, the distribution of yellow tang is strongly influenced by the distribution of finger coral habitats because of ontogenetic shifts in habitat use by recruits and juveniles (Figs. 6 \& 7).

Recruit density was high in Honokohau even though this area has a lower abundance of finger coral substrate and aggregate finger and lobe coral-rich areas compared to Puako and Anaehoomalu (Fig. 5, Table 3). Recruitment variation among sites may be the result of several factors such as spatial variation in recruitment, movement and/or differential postsettlement mortality due to differential shelter from predation (Hixon \& Beets 1993, Carr \& Hixon 1995, Sale 2004). Alternatively, variation in recruitment among sites may result from area effects such that sites with smaller finger coral areas could have the same recruitment as sites with larger finger coral area, but end up with substantially high densities due to its smaller total area. Some of these sources of variation could be addressed by looking at recent studies. First, long-term data shows that the recruitment patterns among sites has been similar among years. From 1999 to 2004, there has been consistently higher recruitment at Honokohau relative to Anaehoomalu and Puako (B. N. Tissot \& W. J. Walsh unpubl. data). Second, the early juvenile stages of yellow tang have small ranges and rarely move from the settlement habitat (Parrish \& Claisse 2006). Third, density calculations were made to include discrepancies in the reef area and length among sites in order to account for possible area effects in the present study. Thus, the present study suggests that while differences in habitat (i.e. finger coral) may play a role in determining the abundance and distribution of recruits, these effects are influenced by other sources of variation that are not discernable among sites. Recruitment variation may be driven by a multiplicity of factors that will determine larval supply, active habitat selection and differential post-settlement mortality, which in turn depends on the availability of habitat, food and predators (Sale 2004). However, a more detailed study is required to test these hypotheses before any conclusions can be made as to why the spatial distribution of recruits is different among sites.

The distribution of juveniles varied greatly among habitats and sites. The wide range of habitat utilization by juveniles may reflect size-dependent processes weakening habitat selection as the species grows (Dahlgren \& Eggleston 2001) or the continued effects of variation in predation intensity. Conversely, shifts in habitat use may not have been as distinct in some sites where aggregations of coral-rich habitats were abundant. The abundance of adults $(\geq 14.0 \mathrm{~cm})$ was greater in shallow turf-rich boulder habitats, although their distribution varied greatly among and within sites (Figs. 6 \& 7). The wide distribution of adults within shallow boulder areas along the reef flat and deep aggregation of coral-rich areas along the reef slope and cliff edge may reflect the availability and proximity of shelter and foraging habitats necessary for growth and reproduction. These results also follow observations made on adult movement where adults have been observed moving between foraging (shallow turf-rich boulder) and refuge (deep aggregate coral-rich) habitats (Walsh 1984).

\section{Applications to MPA design and management}

Empirical studies have shown that MPA size and the abundance and distribution of habitats are important to managed species and can influence the effectiveness of MPAs to protect targeted fish species (Sala et al. 2002, Friedlander et al. 2003, 2007, Gladstone 2006). Our findings that appropriate habitat type for early life history stages, large areas of these habitats on the reef and proximity of appropriate recruit, juvenile and adult habitats were associated with an FRA showing effective replenishment (i.e. significant increases in yellow tang) are consistent with these general conclusions. Even though the FRAs in the present 
study were not replicated, replicate plots within each site revealed that differences between the 2 FRAs were robust. For example, Anaehoomalu (significant replenishment), with the largest reef area and abundance of recruit, juvenile and adult habitats, had the greatest number of yellow tang in each life stage, while Honokohau (no significant replenishment) had the fewest. In addition, overall recruit abundance was lower in the Honokohau FRA, with less than $6 \%$ aggregate finger and lobe coral-rich habitats, compared to the Anaehoomalu FRA where recruit habitat is more than $52 \%$ (Table 3). However, recruit densities in Honokohau were high relative to Puako and Wawaloli. One explanation for high recruit density and no significant replenishment in Honokohau may be differences in the availability of habitats. For instance, the availability of reef habitats can affect the post-settlement demography of reef-fish directly by providing refuge from predation (Hixon \& Beets 1993). For example, the Honokohau site may have high recruitment, but few individuals survive to adulthood due to a lack of available habitat suitable for recruits. Thus, the effectiveness of the Anaehoomalu and Honokohau FRAs to replenish aquarium fish population may be driven by the reef size, abundance and distribution of essential fish habitats. Efforts are under way to examine habitat use pattern of other targeted fish species for all 9 FRAs in West Hawaii and how it relates to the effectiveness of the West Hawaii FRA system in replenishing aquarium fish populations.

Based on these results, it would be prudent to incorporate habitat essential to targeted species in future MPA design. For example, the present study suggests that for effective management of populations of yellow tang, sites should contain high abundance of aggregations of finger and lobe coral distributed at various depths (i.e. 7 to $25 \mathrm{~m}$ ) adjacent to colonized boulders with low to high turf algae (10 to $80 \%$ ) and high coral cover (50 to $80 \%$ ) at a range of depths (i.e. 0 to $30 \mathrm{~m})$.

\section{CONCLUSIONS}

Even though the FRAs were established in 1999, no comprehensive evaluation of the effectiveness of FRAs in relation to the abundance and distribution of habitats had been conducted until now. Findings from the present study suggest that habitat characteristics may largely contribute to the effectiveness of MPAs to replenish the targeted reef-fish, although there are certainly other important factors as well. Current efforts in Hawaii, focused on improving management of the fishery, should therefore incorporate habitats identified in the present study to the design and management of MPAs. MPAs will be more effective at protecting reef-fish species, life stages and the mechanisms that regulate them if they include habitats important to managed species (Sala et al. 2002). This information will help improve management of MPAs, enhance marine ecosystem conservation by identifying locations for future MPAs and provide valuable information to develop cogent resource management practices in Hawaii and other tropical regions.

Acknowledgements. We thank W. Walsh, B. Carmen, S. Cotton, I. Williams, S. Thompson and K. Stamoulis for logistical and fieldwork support. Thanks to J. Claisse and the Tang Team for comments and support. T. Battista, M. Kendall, L. Wedding and $\mathrm{S}$. Miles provided comments and guidance on mapping benthic habitats. Many thanks to friends and volunteers for their help. The paper benefited from comments by 3 anonymous reviewers. The research was supported with grants from the NOAA Habitat Conservation Program, NA04NMF4630374, Hawaii Coral Reef Initiative Research Program and Washington State University Vancouver Science Program. This work is a chapter from the senior author's PhD dissertation.

\section{LITERATURE CITED}

Aburto-Oropeza O, Balaart EF (2001) Community structure of reef fish in several habitats of a rocky reef in the Gulf of California. PSZN I: Mar Ecol 22:283-305

Armstrong RA, Singh H, Torres J, Nemeth RS and others (2006) Characterizing the deep insular shelf coral reef habitat of the Hind Bank marine conservation district (US Virgin Islands) using the Seabed autonomous underwater vehicle. Cont Shelf Res 26:194-205

Beets JP, Hixon MA (1994) Distribution, persistence and growth of groupers (Pisces:Serranidae) on artificial and natural patch reefs in the Virgin Islands. Bull Mar Sci 55:470-483

Bird C (2003) Ecological analysis of digital photographs. www.photogrid.netfirms.com. Accessed 3 Oct

Carr MH, Hixon MA (1995) Predation on early post-settlement survivorship of coral reef fishes. Mar Ecol Prog Ser 124:31-42

Christensen JD, Jeffrey CFG, Caldow C, Monaco ME, Kendall MS, Appledorn RS (2003) Cross-shelf habitat utilization patterns of reef fishes in southwestern Puerto Rico. Gulf Caribb Res 14:9-27

Coyne MS, Monaco ME, Anderson M, Smith W, Jokiel P (2001) Classification scheme for benthic habitats: main eight Hawaiian Islands Biogeography program. US Department of Commerce, National Oceanic and Atmospheric Administration, National Ocean Service, Silver Spring, USA

Coyne MS, Battista TA, Anderson M, Waddell J and others (2003) Benthic habitats of the main Hawaiian islands. NOAA Technical Memorandum NOS NCCOS CCMA 152:1-48

Dahlgren CP, Eggleston DB (2000) Ecological processes underlying ontogenetic habitat shifts in a coral reef fish. Ecology 81:2227-2240

Dahlgren CP, Eggleston DB (2001) Spatio-temporal variability in abundance, size and microhabitat associations of early juvenile Nassau grouper Epinephelus striatus in an offreef nursery system. Mar Ecol Prog Ser 217:145-156

Department of Land and Natural Resources (DLNR) (1996) 
Hawaii fishing regulations. Division of Aquatic Resources, DLNR, Honolulu, HI

Depczynski M, Bellwood DR (2004) Microhabitat utilization patterns in cryptobenthic coral reef fish communities. Mar Biol 145:455-463

Doherty JB, Williams DM (1988) The replenishment of coral reef fish populations. Oceanogr Mar Biol Annu Rev 26: 487-551

Eggleston DB (1995) Recruitment in Nassau grouper Epinephelus striatus: post-settlement abundance, microhabitat features, and ontogenetic habitat shifts. Mar Ecol Prog Ser 124:9-22

ESRI (Environmental Science Research Institute) (2002) ET spatial techniques. ET GeoWizards for ArcGIS, Pretoria

Fowler AJ (1990) Spatial and temporal patterns of distribution and abundance of chaetodontid fishes at One Tree Reef, southern GBR. Mar Ecol Prog Ser 64:39-53

Fowler AJ, Doherty PJ, Williams DMcB (1992) Multi-scale analysis of recruitment of a coral reef fish on the Great Barrier Reef. Mar Ecol Prog Ser 82:131-142

Friedlander AM, E Brown (2003) Fish habitat utilization patterns and evaluation of the efficacy of marine protected areas in Hawaii: integration and evaluation of NOS digital benthic habitats maps and reef fish monitoring studies. Final Report to NOAA National Ocean Service Biogeography Program, Honolulu, HI: 1-78

Friedlander AM, Parrish JD (1998) Habitat characteristics affecting fish assemblages on a Hawaiian Reef. J Exp Mar Biol Ecol 224:1-30

Friedlander AM, Brown EK, Jokiel PL, Smith WR, Rodgers KS (2003) Effects of habitat, wave exposure, and marine protected area status on coral reef fish assemblages in the Hawaiian archipelago. Coral Reefs 22:291-305

Friedlander AM, Brown E, Monaco ME (2007) Coupling ecology and GIS to evaluate efficacy of Marine Protected Areas in Hawaii. Ecol Appl 17:715-730

> Gladstone W (2006) Requirements for marine protected areas to conserve the biodiversity of rocky reef fishes. Aquat Conserv: Mar Freshw Ecosyst 17:71-87

Gratwicke B, Speight MR (2005) The relationship between fish species richness, abundance and habitat complexity in a range of shallow tropical marine habitats. J Fish Biol 66:650-667

Green AL (1996) Spatial, temporal and ontogenetic patterns of habitat use by coral reef fishes (Family Labridae). Mar Ecol Prog Ser 133:1-11

Hixon MA, Beets JP (1993) Predation, prey refuges, and the structure of coral reef fish assemblages. Ecol Monogr 63:77-101

Hixon MA, Mark HC (1997) Synergistic predation, density dependence, and population regulation in marine fish. Science 277:946-949

Hixon MA, Webster MS (2002) Density dependence in reef fish populations In: Sale PF (ed) Coral reef fishes: dynamics and diversity in a complex ecosystem. Academic, San Diego, CA, p 303-325

Holm S (1979) A simple sequentially rejective multiple test procedure. Scand J Stat 6:65-70

Jenness J (2005) Random point generator 1.3v. Jenness Enterprises, Flagstaff, USA

Kendall MS, Kruer CR, Buja KR, Christensen JD, Finkbeiner M, Monaco ME (2001) Methods used to map the benthic habitats of Puerto Rico and the US Virgin Islands. National Ocean Service, Center for Coastal Monitoring and Assessment, Biogeography Program, Silver Spring, MD

Kendall MS, Christensen JD, Hillis-Starr Z (2003) Multi-scale data used to analyze the spatial distribution of French grunts, Haemulon flavolineatum, relative to hard and soft bottom in a benthic landscape. Environ Biol Fishes 66: $19-26$

Levin PS (1991) Effects of microhabitat on recruitment variation in a Gulf of Maine reef fish. Mar Ecol Prog Ser 75: 183-189

$>$ Levin SA (1992) The problem of pattern and scale in ecology. Ecology 73:1943-1967

> Meekan MG, Choat JH (1997) Latitudinal variation in abundance of herbivorous fishes: a comparison of temperate and tropical fishes. Mar Biol 128:373-383

- Menge BA, Lubchenco J, Ashkenas LR (1985) Diversity, heterogeneity and consumer pressure in a tropical rocky intertidal community. Oecologia 65:394-405

Nanami A, Nishihira M (2002) The structure and dynamics of fish communities in an Okinawan coral reef: effects of coral-based habitat structures at sites with rocky and sandy sea bottoms. Environ Biol Fishes 63:353-372

Nasby-Lucas NM, Embley BE, Hixon MA, Merle SG, Tissot BN, Wright DJ (2002) Integration of submersible transect data and high-resolution multibeam sonar imagery for a habitat-based groundfish assessment of Heceta Bank, Oregon. Fish Bull (Wash DC) 100:739-751

Parrish JD, Claisse JT (2006) Post-settlement life history of key coral reef fishes in a Hawaiian marine protected area network. NOAA Final Project Report, Honolulu, HI 1-42

Parsons DM, Shears NT, Babcock RC, Haggit TT (2004) Finescale habitat change in a marine reserve, mapped using radio-acoustically positioned video transects. Mar Freshw Res 55:257-265

Pimentel RA (1979) Morphometrics, the multivariate analysis of biological data. Kendall-Hunt, Dubuque, IA

Sala E, Aburto-Oropeza O, Paredes G, Parra I, Barrera JC, Dayton PK (2002) A general model for designing networks of marine reserves. Science 298:1991-1993

> Sale PF (2004) Connectivity, recruitment variation, and structure of reef-fish communities. Integr Comp Biol 44: 390-399

SAS Institute (2000) JMP statistics and graphics guide, Version 4.00. SAS Institute, Cary, NC

Schneider DC, Walters R, Thrush S, Dayton P (1997) Scale-up of ecological experiments: density variation in the mobile bivalve Macomona liliana. J Exp Mar Biol Ecol 216: 129-152

SHOALS LIDAR Bathymetry (2002), accessed March 2005, http://shoals.sam.usace.army.mil/hawaii/pages/Hawaii_ Data.htm

Stanbury K, Starr RM (1999) Applications of Geographic Information Systems (GIS) to habitat assessment and marine resource management. Oceanol Acta 22:699-703

Ter Braak CJF (1986) Canonical Correspondence Analysis: a new eigenvector technique for multivariate direct gradient analysis. Ecology 67:1167-1179

Tissot BN, Hallacher LE (2003) The effects of aquarium collectors on coral reef fishes in Hawaii. Conserv Biol 17: $1759-1768$

Tissot BN, Walsh WJ, Hallacher LE (2003) Evaluating the effectiveness of a marine reserve in West Hawaii to improve management of the aquarium fishery. NOAA Tech Rep, Honolulu, HI, 1-20

Tissot BN, Walsh WJ, Hallacher LE (2004) Evaluating the effectiveness of a marine reserve network in Hawaii to increase the productivity of an aquarium fishery. Pac Sci 58:175-188

Tolimieri N (1995) Effects of microhabitat characteristics on the settlement and recruitment of a coral reef fish at two spatial scales. Oecologia 102:52-63 
Tupper M, Boutilier RG (1995) Effects of habitat on settlement, growth, and post-settlement survival of Atlantic cod (Gadus morhua). Can J Fish Aquat Sci 52: $1834-1841$

Underwood AJ, Chapman MG, Connell SD (2000) Observation in ecology: you can't make progress on processes without understanding the patterns. J Exp Mar Biol Ecol 250:97-115

Walsh WJ (1984) Aspects of nocturnal shelter, habitat space, and juvenile recruitment in Hawaiian coral reef fishes. $\mathrm{PhD}$ dissertation, University of Hawaii, Honolulu, HI

Walsh WJ (1985) Reef fish community dynamics on small artificial reefs: the influence of isolation, habitat structure, and biogeography. Bull Mar Sci 36:357-376

Walsh WJ (1987) Patterns of recruitment and spawning in Hawaiian reef fishes. Environ Biol Fishes 18:257-276

Walsh WJ, Cotton SP, Dierking J, Williams ID (2004a) The

Editorial responsibility: Charles Birkeland,

Honolulu, Hawaii, USA commercial marine aquarium fishery in Hawaii 19762003. In: Friedlander AM (ed) Status of Hawaii's coastal fisheries in the new millennium, revised. Proceedings of the 2001 fisheries Symposium sponsored by the American Fisheries Society, Hawaii Chapter. Honolulu, HI, p 132-159

Walsh WJ, Tissot BN, Hallacher L (2004b) A report on the finding and recommendations of effectiveness of the West Hawaii Regional Fishery Management Area. Department of Land and Natural Resources (DLNR), Honolulu, HI

> Watson RA, Carlos GM, Samoilys MA (1995) Bias introduction by the non random movement of fish in visual transect surveys. Ecol Modell 77:205-214

- Wiens JA (1989) Spatial scaling in ecology. Funct Ecol 3: 385-397

Zar JH (1984) Biostatistical analysis. Prentice Hall, Englewood Cliffs, NJ

Submitted: March 29, 2006; Accepted: March 17, 2008

Proofs received from author(s): July 22, 2008 